\title{
ANÁLISE CONJUNTURAL DA INDÚSTRIA DE MEDICAMENTOS GENÉRICOS NO BRASIL NO PERÍODO DE SETEMBRO DE 2001 A AGOSTO DE 2002
}

\section{CONJUNCTURAL ANALYSIS OF THE GENERIC DRUG INDUSTRY IN BRAZIL BETWEEN SEPTEMBER 2001 AND AUGUST 2002}

\author{
Adiléia Ribeiro Santos \\ 1 Faculdade Jaguariaiva - FAJAR, Curso de Direito, Jaguariaiva, PR, Brasil e Faculdade \\ de Telêmaco Borba - FATEB, Telêmaco Borba, PR; (42) 223-1878; \\ e-mails: adileia@pop.com.br e adi.ribeiro@zipmail.com.br
}

Recebido para publicação em 12/09/2003

Aceito para publicação em 10/08/2004

\section{RESUMO}

O que propomos neste trabalho é discutir a evolução do mercado de medicamentos genéricos no Brasil de setembro de 2001 a agosto de 2002. Com base em alguns slides referentes ao XXXIV Congresso da Sociedade Brasileira de Farmacologia e Terapêutica Experimental. "Política de Medicamentos Genéricos no Brasil”, faz-se uma análise conjuntural para melhor compreender esse novo segmento de mercado. O texto trata da organização do mercado de medicamentos no Brasil, dos aspectos legais importantes, dos objetivos dos medicamentos genéricos, da percepção da população e dos médicos (apesar de não haver dados suficientes para essa averiguação), do impacto dos medicamentos genéricos no mercado farmacêutico, dos benefícios que eles trazem ao país, da evolução de sua indústria e do mercado deles no Brasil.

Palavras-chave: medicamentos genéricos, estado, sociedade, medicamentos de marca, indústria

\begin{abstract}
The aim of this paper is to discuss the evolution of the generic drug market in Brazil from September 2001 through August 2002. Drawing on some slides from the 34th Congress of the Brazilian Society of Pharmacology and Experimental Therapeutics - the theme of which was "Generic Drug Policy in Brazil “-, a conjunctural analysis is carried out in order to better understand this new segment
\end{abstract}


of the market. The text addresses the organization of the medicine market in Brazil; the relevant legal aspects; the purposes of generic drugs; the perception of the population and the doctors, even though there is not enough data for this investigation; the impact of generic drugs on the pharmaceutical market; the benefits they bring to the country; the development of the generic drug industry, and their market in Brazil.

Key words: generic drugs, state, society, brand-name medicines, industry

\section{Uma análise da indústria farmacêutica no Brasil}

A indústria farmacêutica é considerada um dos empreendimentos mais lucrativos do mundo, só o seu faturamento anual, de acordo com Brandão (1999), está na casa dos U\$ 12 bilhões, o que representa um ganho superior ao de muitos setores da economia.

Serra (2000, p. 105) afirma que:

O mercado farmacêutico mundial é dinâmico e complexo: tem crescimento de cerca de $7 \%$ ao ano e já foi comparado, pelo ritmo de inovação, ao setor de tecnologias de informação. Diante da diversidade dos seus produtos e do tamanho das suas empresas, aproxima-se da indústria alimentícia; pelo volume de faturamento, alcança a indústria bélica.

Frente às condições precárias de saúde que atravessam os países do Terceiro Mundo, os meios ligados ao problema levantaram o conceito de medicamento essencial, em que através do consenso entre os médicos, 250 a 300 fármacos são suficientes para tratar a maioria das enfermidades, podendo deste modo, atender à maioria da população carente, com um número pequeno de medicamentos.

Com a competitividade e o lucro crescente devido à globalização financeira, o universo econômico teve que enfrentar profundas mudanças.

De acordo com o CODETEC (1991), o Brasil é um dos maiores mercados farmacêuticos do mundo mas a maior parte da população não tem condições de adquirir medicamentos essenciais para o seu tratamento ou uso contínuo. Diante desta afirmação, chama-se a atenção para a necessidade de incluir os produtos farmacêuticos no âmbito da questão social, considerando que afetam diretamente a saúde das nações, mais do que qualquer produto de outro segmento industrial.

Estimativas da Organização das Nações Unidas (ONU) indicam que os medicamentos respondem por $40 \%$ a $50 \%$ dos gastos em saúde pública em muitos países desenvolvidos. Isso justifica o fato de o mercado mundial de medicamentos ser marcado pela forte intervenção governamental, apesar do domínio de grandes empresas privadas multinacionais.

O apoio governamental, através de diversos instrumentos, foi um dos grandes responsáveis pelo avanço da produção farmoquímica na década de 1980. Segundo Chan (1998), no seguimento de genéricos, o avanço que parte de moléculas conhecidas trouxe um crescimento significativo nesta década.

Teixeira (1985), acrescenta que é marcante a intervenção do Estado no setor saúde, seja pela produção direta de serviços, ou pelo seu financiamento, organização e regulação do mercado. Isso se manifesta nos crescentes gastos públicos com a função saúde nos diversos países.

Para Queiroz (1993), existem diversas razões para que os governos intervenham na produção e comercialização de remédios. Seriam elas: a responsabilidade de prover à população condições de saúde adequadas, considerando os elevados custos dos sistemas de saúde de muitos países; a necessidade da preocupação com a oferta de medicamentos, evitando seu emprego supérfluo e preços excessivamente elevados; e a necessidade de um sistema de proteção patentária em função da facilidade de imitação face aos custos e dificuldades da inovação, visto que as moléculas já são conhecidas.

A indústria farmacêutica focava a lucratividade; agora com a introdução dos medicamentos genéricos a saúde e o bem-estar do consumidor passaram a ter 
grande relevância. Ou seja, com a introdução dos medicamentos genéricos, a indústria farmacêutica passou a ofertar seus medicamentos com preços mais acessíveis e até mais baratos que os genéricos.
No Brasil, o futuro da indústria farmacêutica nacional começou a ser traçado com a implantação da Lei das Patentes ${ }^{1}$ em 1996, na qual patentes representavam uma espécie de monopólio provisório.

Quadro 1 - A Organização do Mercado de Medicamentos no Brasil.

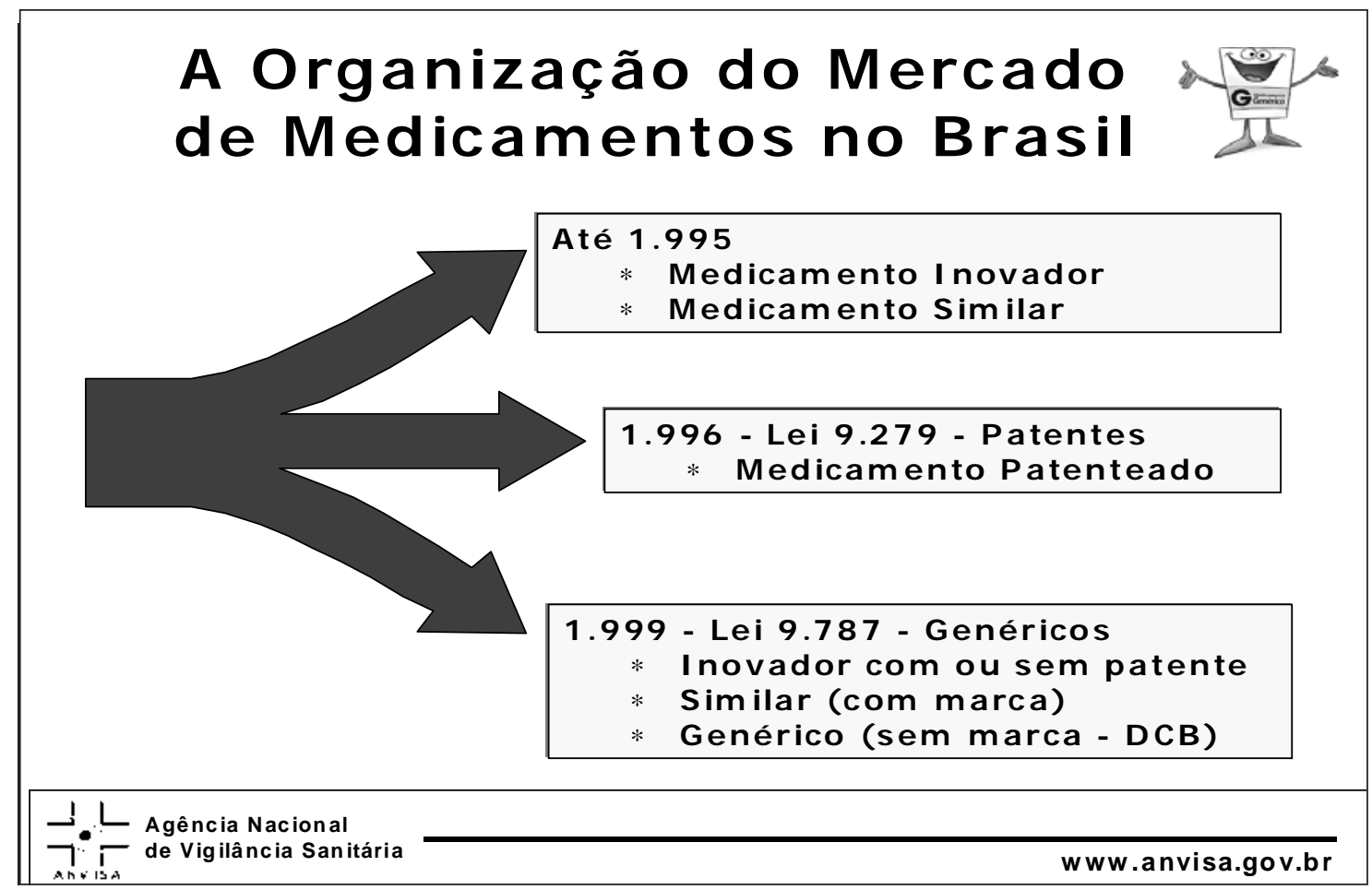

Fonte: < www.anvisa.gov.br/hotsite/genericos/index.htm >

Medicamento Inovador - Em geral, é aquele com marca, autorizado, em primeiro lugar, para comercialização (normalmente como medicamento patenteado), com base na documentação de eficácia, segurança e qualidade reconhecida pela autoridade sanitária nacional. Quando um medicamento está disponível há muitos anos, pode não ser possível identificá-lo como produto farmacêutico inovador. Revista Genéricos Pró Saúde. São Paulo, ano I, n. 1, p. 18, maio 2001.

Medicamento Similar - É aquele que contém os mesmos princípios ativos, as mesmas concentrações, as mesmas formas farmacêuticas, a mesma via de administração, a mesma indicação terapêutica, a mesma posologia e que é equiavente ao medicamento de referência, podendo diferir somente em características de tamanho, forma, embalagem, prazo de validade, rotulagem e excipientes. Revista Genéricos Pró Saúde. São Paulo, ano I, n. 1, p. 18, maio 2001.

Cada medicamento está protegido por patente, bem como todo produto industrial que atribui a seu detentor a exclusividade temporária para sua produção e comercialização.

A patente começa a vigorar desde o momento em que o fabricante faz a solicitação. Durante o tempo de exclusividade de comercialização, que geralmente dura 20 anos, que vai do lançamento no mercado até a data de expiração da patente, o produtor é livre para explorar seus direitos sozinho ou dividi-los com outro fabricante.

${ }^{1}$ Lei das Patentes - Lei 9279 de 14 de maio de 1996 refere-se à Lei das Patentes que regula direitos e obrigações relativos à propriedade industrial. 
De acordo com LA REVUE PRESCRIRE (1992), no caso dos medicamentos, após o vencimento da patente do princípio ativo, qualquer especialidade farmacêutica pode legalmente ser copiada, mediante uma especialidade dita genérica, que será comercializada sob Denominação Comum Internacional (DCI) ou novo nome de marca (visto que os nomes de marca são protegidos), por um fabricante especializado, ou não, em genéricos.

Uma outra forma de intervenção do Estado na indústria de medicamentos, foi a criação da Lei 9.787 de 10 de fevereiro de 1999, a qual estabelece o medicamento genérico ${ }^{2}$, dispondo a utilização de nomes genéricos em produtos farmacêuticos.

A Lei 9.787 (do $n^{\circ} 29$, de 11 de fevereiro de 1999) de origem remota, começou a ser proposta no ano de 1991, quando o deputado Eduardo Jorge do PT-SP (Partido dos Trabalhadores) que apresentou o projeto $n^{\circ} 2.022$ almejando somente a identificação de produtos farmacêuticos pelo nome genérico, com destaque inferior do nome do laboratório fabricante e nome correspondente das marcas comerciais ou de fantasia do produto.

Em 1993, o Presidente Itamar Franco, promulgou o decreto $\mathrm{N}^{\circ} 793$ que promovia a disseminação do uso do nome genérico como estratégia para baratear os medicamentos: as pessoas deixariam de valorizar as marcas e buscariam o medicamento de menor preço. No entanto, ele foi boicotado pela indústria. Mas o projeto dos medicamentos genéricos, que ficou encerrado nas gavetas dos parlamentares governistas, voltou à cena no ano de 1999, no Governo de Fernando Henrique Cardoso, quando foi promulgado.

A Lei número 9.787, que regulariza os medicamentos genéricos, dispondo sobre a utilização desse nome em produtos farmacêuticos, estabeleceu bases legais para a instituição desses medicamentos no Brasil, onde eles passaram a ser uma alternativa para a saúde do brasileiro.

De acordo com a SOBRAVIME - Sociedade Brasileira de Vigilância de Medicamentos - (1999), com a promulgação da Lei dos Genéricos, a emissão da Resolução da Agência Nacional de Vigilância Sanitária (ANVISA) N 391, de 09 de agosto de 1999 (Regulamento Técnico para Medicamentos Genéricos) e a regulamentação da Lei 9.787/99 - o Decreto n ${ }^{\circ}$ 3.181 de 21 de setembro de 1999, criaram-se as principais bases legais para o que vem sendo chamado de desenvolvimento de uma "política de genéricos".

No Brasil a implantação dos medicamentos genéricos deu-se de forma rápida, se comparada com a de outros países, que chegaram a levar cerca de dez anos para que a política de medicamentos genéricos fosse implantada.

De acordo com Bermudez (2000), a implantação de programas e políticas de medicamentos genéricos vem sendo proposta há vários anos pela OMS (Organização Mundial de Saúde). A implantação desses visa ampliar o acesso da população aos remédios, romper os monopólios das marcas e reduzir os preços dos medicamentos no mercado farmacêutico.

O medicamento genérico é aquele que tem as mesmas características e produz no corpo os mesmos efeitos que o de marca (medicamento de referência, comercializado no Brasil). A diferença é que ele não tem nome comercial, mas é vendido pelo princípio ativo, ou pelo nome genérico, além de ser muito mais barato. Por ser igual ao medicamento de marca e por não precisar de investimento em pesquisa para seu desenvolvimento e nem publicidade para a marca, seu custo é menor.

\footnotetext{
${ }^{2}$ Genéricos - são produtos vendidos pelo nome de seu princípio ativo, com características farmacológicas exatamente iguais as de marcas tradicionais. Seu efeito é tão eficaz quanto o dos demais medicamentos. A garantia de qualidade é comprovada pelos testes de biodisponibilidade (que provam que o princípio ativo contido no medicamento é liberado e absorvido pelo organismo, alcançando o objetivo para o qual foi ingerido) e bioequivalência farmacêutica (que demonstra por exames que o medicamento em questão tem a mesma biodisponibilidade que o seu medicamento de referência) realizados pela Agência Nacional de Vigilância Sanitária (ANVISA).
} 
Quadro 2. Genéricos No Brasil Aspectos Legais Importantes.

\section{Genéricos no Brasil Aspectos Legais I m portantes}

Intercambialidade com base na comprovação de bioequivalência

e equivalência farmacêutica

Uso da DCB/DCI - proibido uso de marca

Médicos no SUS - têm que prescrever pela DCB/DCI

Médico particular - prescrição livre e pode proibir troca da receita

Farmacêutico pode trocar receita da marca pelo genérico

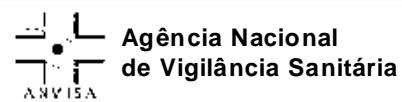

Fonte: < www.anvisa.gov.br/hotsite/genericos/index.htm >

DCB - Denominação Comum Brasileira. $\quad$ DCI - Denominação Comum Internacional.

Conforme a lei, o único médico obrigado a prescrever o medicamento com o nome genérico é o que atende pelo Sistema Único de Saúde (SUS). Já na rede privada, não há essa obrigatoriedade, podendo o profissional, inclusive, pedir na receita que sua indicação não seja substituída na farmácia. Quando não houver essa observação na receita, pela lei, o farmacêutico só poderá trocar o medicamento comercial pelo genérico, nunca pelo similar.

O que se espera de um medicamento é a boa qualidade por um menor preço. Devido a isso, vieram os medicamentos genéricos, os quais possibilitaram uma nova referência de preços aos medicamentos de grande demanda. 


\section{Os objetivos dos medicamentos genéricos}

Quadro 3 - Objetivos

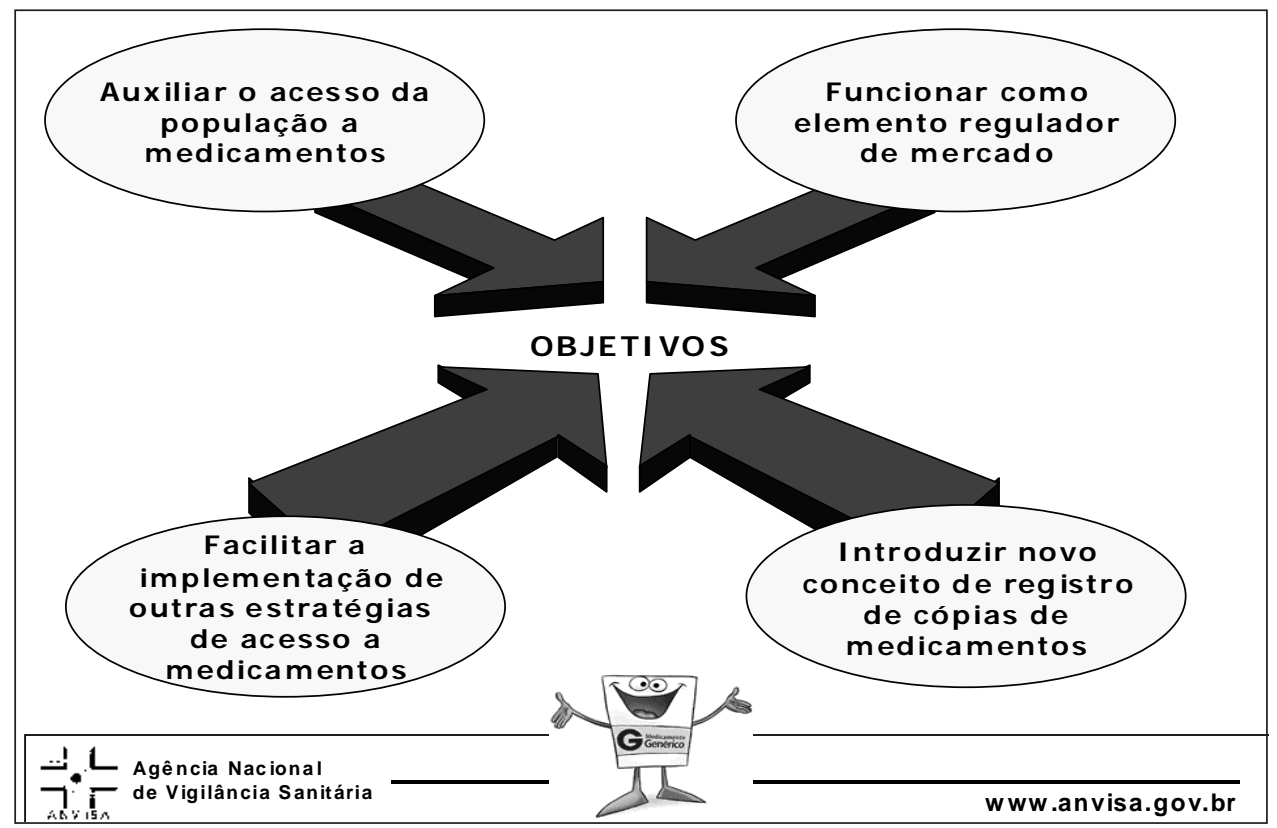

Fonte: < www.anvisa.gov.br/hotsite/genericos/index.htm >

O caráter social foi, sem dúvida, um dos grandes apelos da receptividade à lei de genéricos e uma opção, não só para população, mas sim, para toda a sociedade.

Serra (2001) comenta que seu objetivo com a implantação da Lei dos Genéricos é tornar o medicamento mais acessível a quem precisa dele, visto que 85\% da população com menor poder aquisitivo consome 52\% dos remédios. Isso está estimulando a indústria a produzir medicamentos genéricos a preços mais acessíveis e incentivando o consumidor a fazer uso desses medicamentos.

Bermudez (1995, p. 144) diz que:

A verdadeira execução de uma política de medicamentos genéricos deve ser vista como uma alternativa para o mercado brasileiro, considerando que a experiência de outros países mostrou que efetivamente reduz os preços, ao romper com o monopólio das marcas e propiciar opções à população. Contudo, é indispensável uma série de ações governamentais para garantir a qualidade e equivalência dos produtos licenciados. Santos (1999, p. 09) afirma que:

Temos que pensar nos grandes benefícios que os genéricos trarão ao Brasil. Aqui, aproximadamente um terço da população não tem acesso ao medicamento, por falta de recursos, e os genéricos facilitarão o acesso desses milhões de desassistidos ao tratamento. Além do mais, o SUS terá uma economia de até $40 \%$ em suas despesas com medicamento, o equivalente a 2 bilhões/ano. Foi por essas causas que o Conselho Federal de Farmácia lutou tanto, para que a lei dos genéricos fosse aprovada, no congresso Nacional. (...). Afora essas vantagens sociais, a política de genéricos traz ainda outro ponto positivo: a indústria nacional poderá crescer cerca de $30 \%$, segundo estimativa do diretor-executivo do laboratório Neo Química, Álvaro Zanella, instalado em Anápolis (GO). Isso vai significar a geração de mais empregos. Tudo isso conjugado representa um grande alcance social. É disso que o país precisa.

Na maioria dos países os medicamentos genéricos são mais baratos que os medicamentos de marca.

Para Oliveira (1997, p. 45):

A racionalidade do uso de medicamentos genéricos em países como o Brasil escora-se nos seus preços provavelmente mais baratos, pelo nãopagamento de royalties, no engajamento da indústria nacional na sua produção e na nãovinculação do receituário médico a marcas de 
fantasia, o que, em tese, libertaria o país da influência dos monopólios do setor.

\section{Avanços conseguidos com a implantação dos genéricos}

Quadro 4 - População

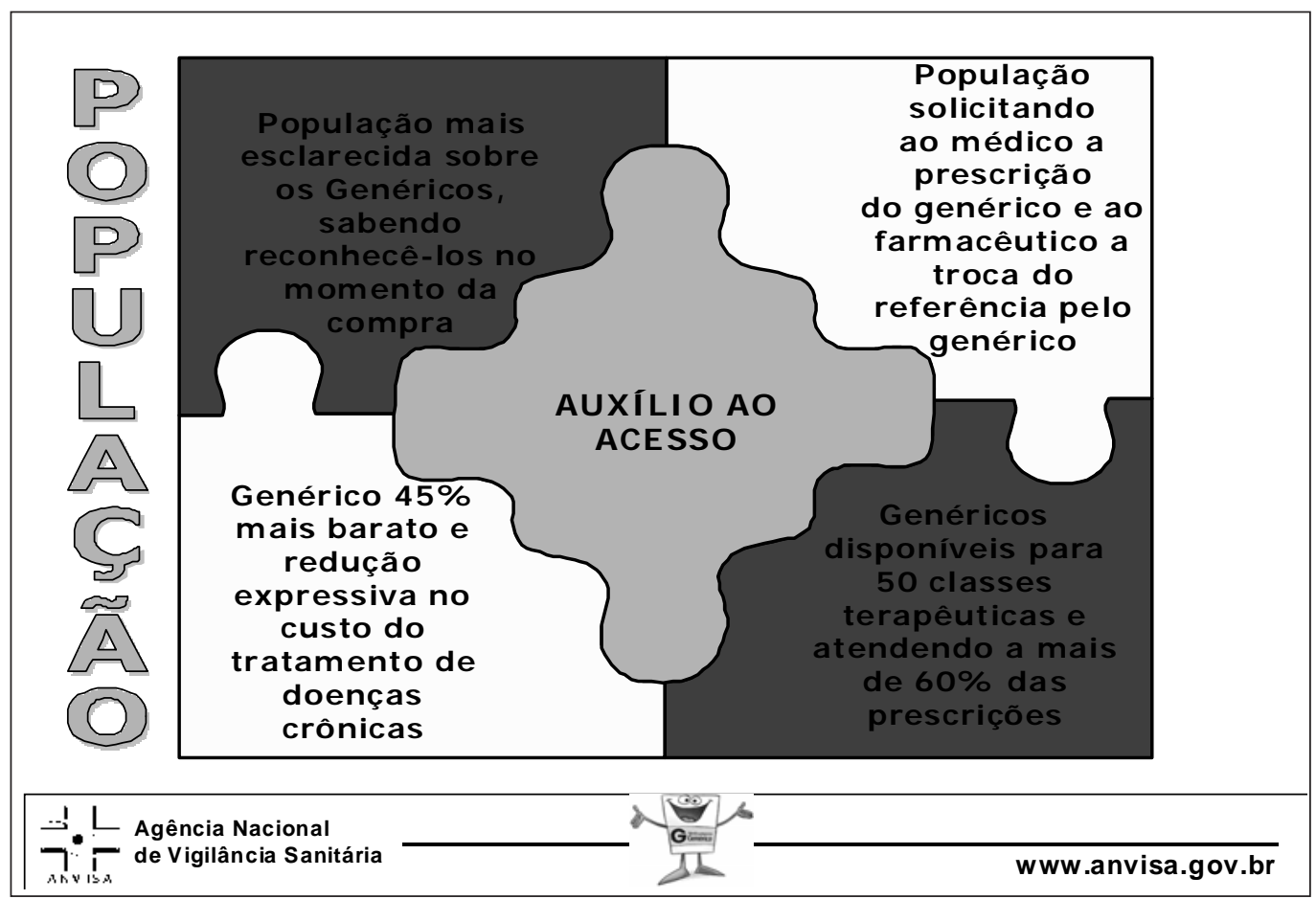

Fonte: < www.anvisa.gov.br/hotsite/genericos/index.htm >

Num país como o Brasil, com tantas pessoas sem acesso a medicamentos, a questão do custo baixo torna-se de vital importância para a população, a qual esbarra na inexistência de uma política de assistência farmacêutica.

Serra (2001, p. 04) cita que:

É lógico que há muito ainda a fazer, mas estamos absolutamente convencidos de que estamos ajudando a criar um mercado de medicamentos mais adaptado à realidade social e econômica do Brasil. Os genéricos estão influenciando positivamente o mercado, injetando um mecanismo de concorrência, reduzindo preços de produtos que até um ano atrás só subiam.

Santos (1999, p. 05) afirma que:

Os preços dos medicamentos sobem despudoradamente, no Brasil, bem acima do índice inflacionário, enquanto os salários dos trabalhadores estão praticamente congelados. Ainda para o referido autor, os genéricos vão beneficiar milhões de cidadãos brasileiros despossuídos, que não conseguem adquirir o medicamento de que necessitam, devido ao seu preço inacessível.

Serra (2001, p. 05) diz que:

Para que o farmacêutico e o consumidor saibam quais são os medicamentos genéricos disponíveis no mercado, é imprescindível que as farmácias e drogarias mantenham em local visível a relação atualizada dos produtos registrados na ANVISA. Isso, aliás, é obrigação determinada em lei.

Serra (2001) diz ainda, que há outros mecanismos para facilitar a identificação e comercialização dos genéricos. No caso das embalagens, além do princípio ativo, elas ganharam uma tarja amarela contendo um grande " $G$ " impresso, além do registro do termo "Medicamento Genérico”. 
Quadro 5 - Percepção da população

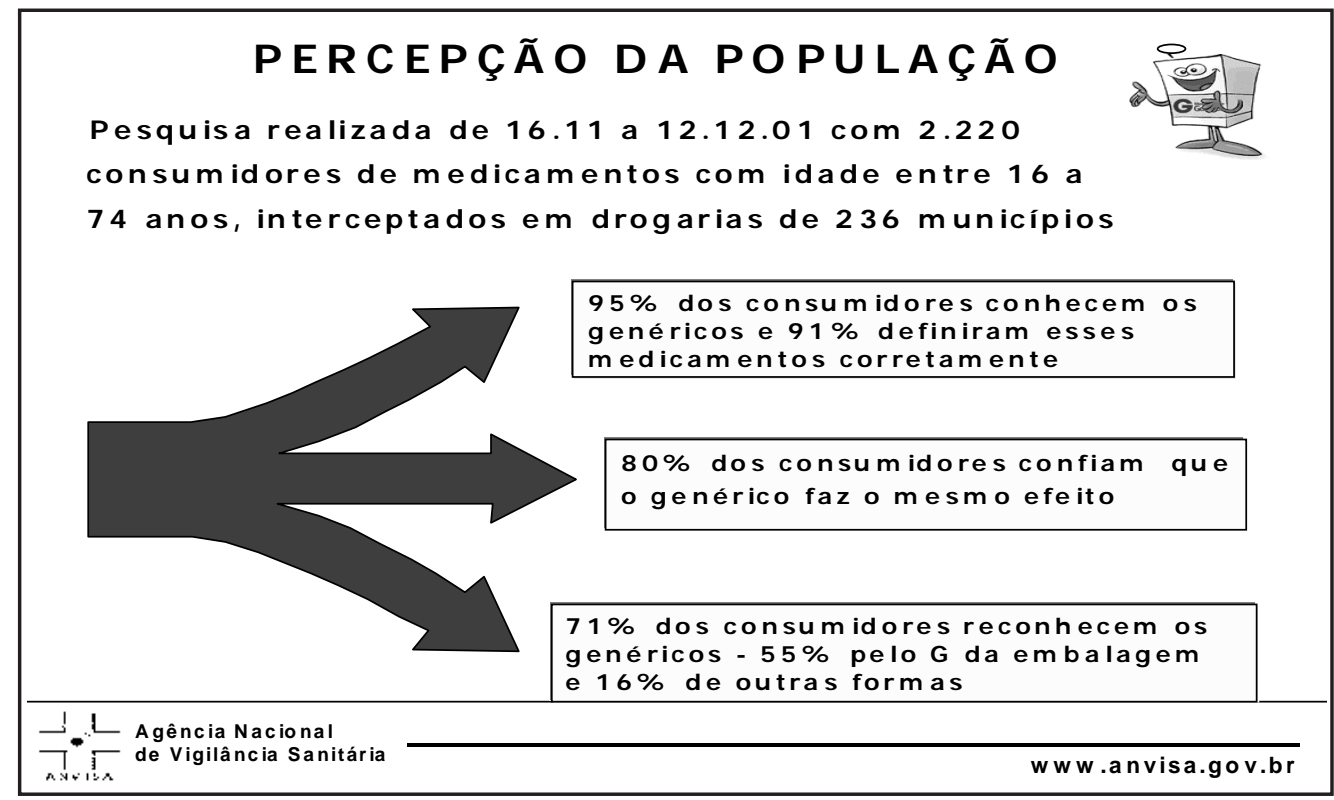

Fonte: < www.anvisa.gov.br/hotsite/genericos/index.htm >

Para Vilardaga1 (2002, p. 01), “diante da possibilidade de comprar genéricos, o consumidor ten- derá a deixar de lado, gradualmente, os medicamentos de referência ${ }^{3}$ e os similares, por razões de preço".

Quadro 6 - Percepção dos médicos

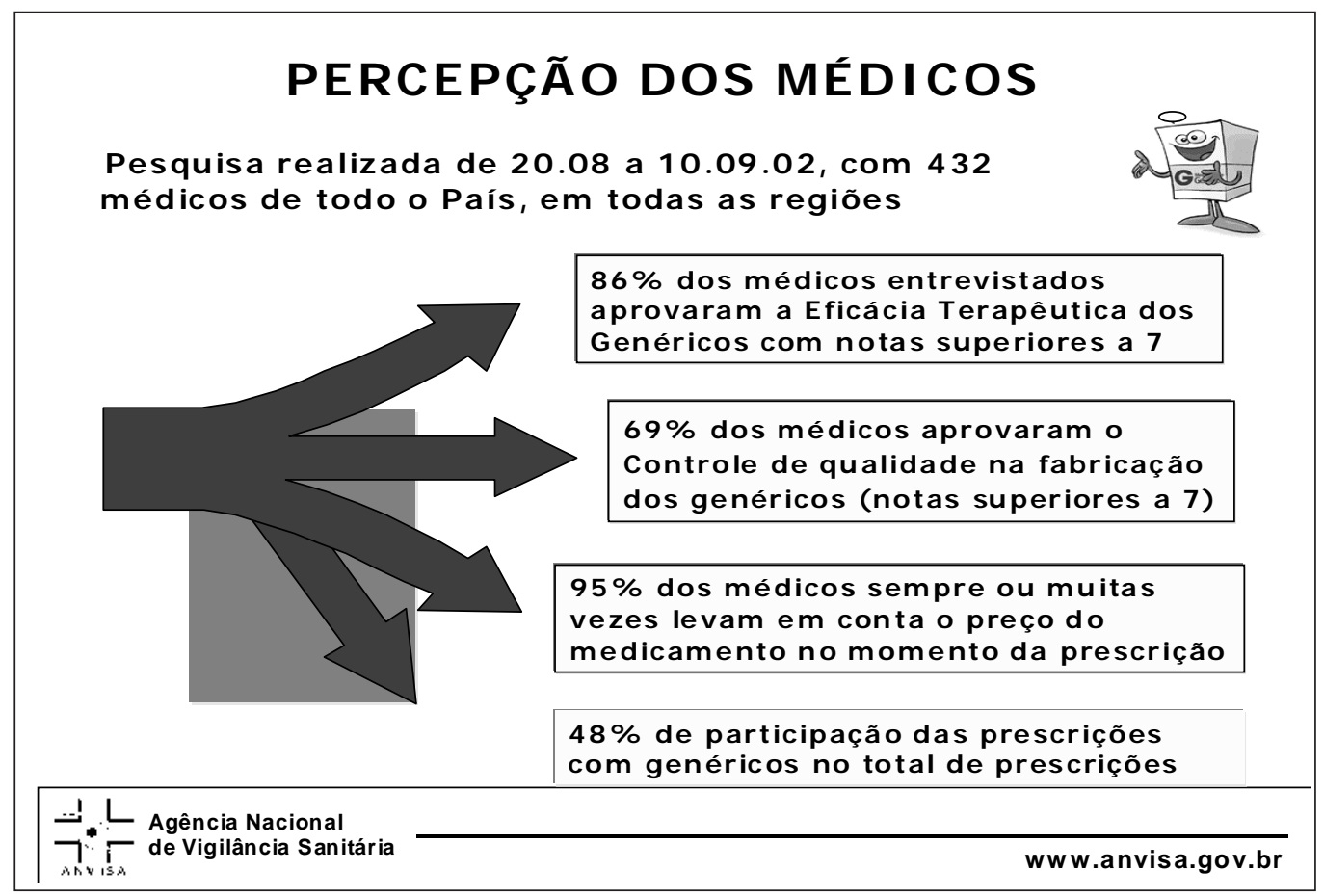

Fonte: < www.anvisa.gov.br/hotsite/genericos/index.htm >

\footnotetext{
${ }^{3}$ Corresponde a um produto comercializado, com o qual outros produtos pretendem ser intercambiáveis. Na maioria dos casos esse medicamento corresponde a um inovador, ou, na sua ausência, ao líder de vendas no mercado, para o qual se comprovam a eficácia, segurança e qualidade. Revista Genéricos Pró Saúde. São Paulo, ano I, n. 1, p. 18, maio 2001.
} 
Neste quadro não ficou claro em que classe médica (pública ou privada) foi realizada essa pesquisa, pois como já foi relatado, o médico da rede pública é o único obrigado a receitar medicamentos genéricos; mas para os da rede privada isso é opcional.

\section{Medicamentos genéricos no mercado brasileiro}

Quadro 7 - Mercado

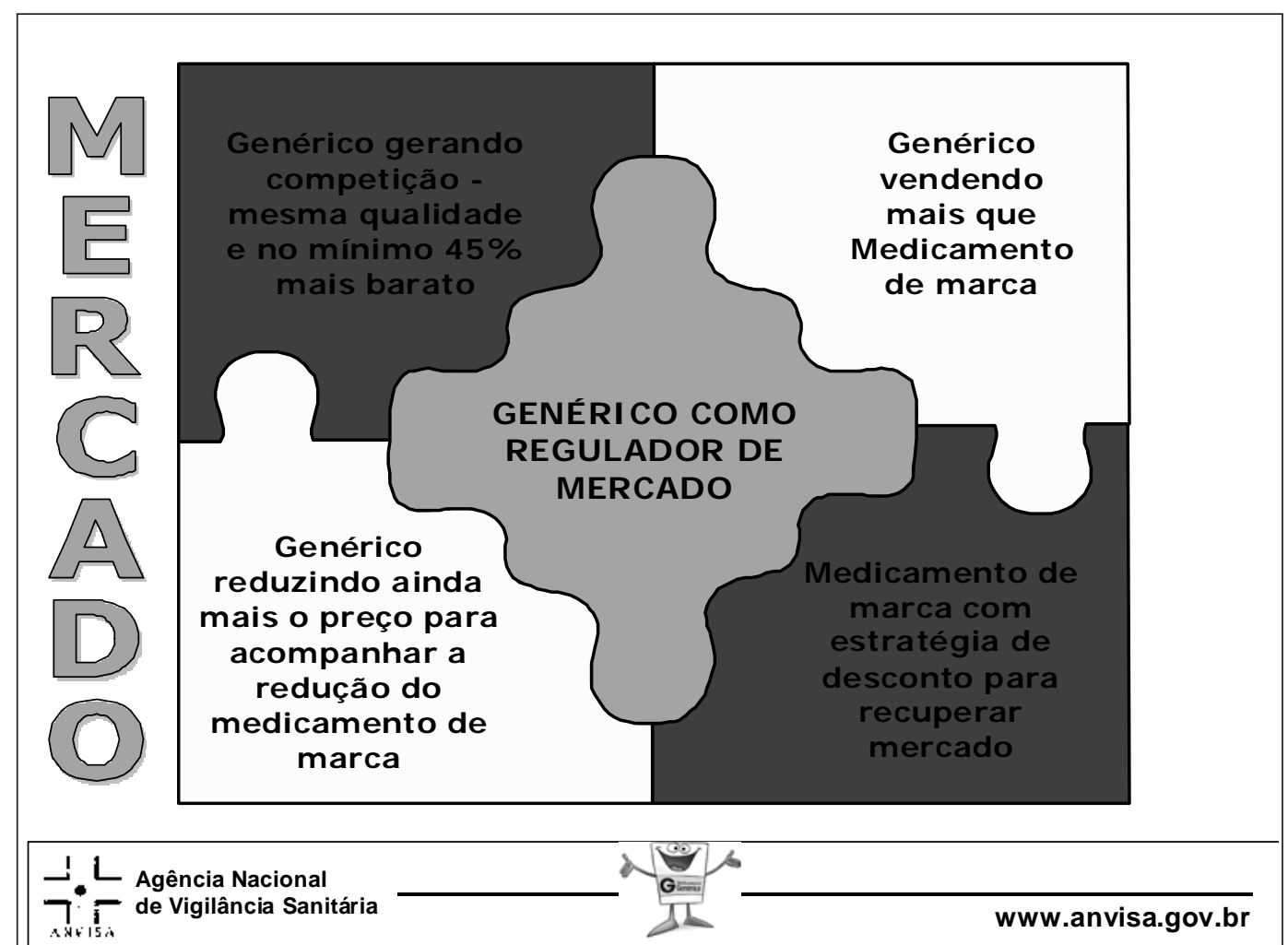

Fonte: < www.anvisa.gov.br/hotsite/genericos/index.htm >

No mercado brasileiro, os medicamentos genéricos representem uma alternativa concreta, mas a existência de produtos com a denominação "genérico" não é suficiente para estabelecer a competitividade necessária e influenciar os preços no mercado.

Em relação ao mercado', Bermudez (1995, p. 144) afirma que:

As indústrias transacionais no Brasil fazem críticas e restrições ao decreto dos genéricos, alegando que a substituição ou a prescrição de medicamentos genéricos vai acarretar problemas com a qualidade dos medicamentos. (...) a questão de acompanhar e assegurar a qualidade dos produtos do mercado é um ponto crucial na implementação de uma política de medicamentos genéricos e deve ser assumida como ação governamental.
De acordo com Vilardaga1 (2002), em 1999, a maioria das marcas líderes no mercado cederam à concorrência dos genéricos e tiveram sua receita reduzida em mais de 75\%, (como é o caso do antiinflamatório Cataflan). E ainda para o autor (2002, p. 01), dentro de cinco ou seis anos, conforme os especialistas, o percentual de inovações de genéricos no mercado será superior a $50 \%$.

As diferenças entre o mercado de genéricos e os medicamentos patenteados são muito importantes para a análise da situação brasileira. Pois existe uma descontinuidade muito grande entre os níveis de capacitação tecnológica, financeira e de marketing requeridos para atuar num e noutro mercado de medicamentos, afirma Queiroz (1993). 
Quadro 8 - Impactos no mercado farmacêutico

\begin{tabular}{|c|c|c|c|c|c|c|}
\hline I mpactos I & \multicolumn{4}{|c|}{ no Mercado Farmacêutico } & \multicolumn{2}{|c|}{ an } \\
\hline Referência & Unid.p/mil & $\%$ * & Genérico & Unid.p/mil & $\% *$ & Total \\
\hline Atenol & 114 & 20 & Atenolol & 302 & 53 & 574 \\
\hline Amoxil & 85 & 8 & Amoxicilina & 694 & 66 & 1059 \\
\hline Amplacilina/Binotal & 59 & 32 & Ampicilina & 93 & 51 & 182 \\
\hline Norvasc & 24 & 9 & Besilato Anlodipino & 75 & 27 & 282 \\
\hline Capoten & 113 & 26 & Captopril & 270 & 62 & 438 \\
\hline Antak & 52 & 12 & Cloridrato Ranitidina & 242 & 57 & 423 \\
\hline Keflex & 133 & 22 & Cefalexina & 359 & 60 & 597 \\
\hline Renitec & 108 & 21 & Maleato Enalapril & 208 & 40 & 521 \\
\hline Peprazol/Losec & 14 & 4 & Omeprazol & 207 & 60 & 343 \\
\hline Glifage & 159 & 31 & Cloridrato Metformina & 201 & 39 & 517 \\
\hline Dados Ago/ 02 & \multicolumn{6}{|c|}{ * Participação no total das vendas } \\
\hline $\begin{array}{l}\text { ZL Agência Nacional } \\
\text { Ż de Vigilância Sanitária }\end{array}$ & \multicolumn{6}{|c|}{ www.anvisa.gov.b } \\
\hline
\end{tabular}

Fonte: < www.anvisa.gov.br/hotsite/genericos/index.htm >

Conforme se pode observar há um aumento nas vendas dos medicamentos genéricos no mercado brasileiro em várias classes terapêuticas.

Com a introdução no Brasil dos medicamentos genéricos, houve uma polêmica gerada pela nova legislação envolvendo tais medicamentos, pois houve um investimento milionário em campanhas de marketing por parte da indústria farmacêutica de capital transnacional na tentativa de dificultar ou inviabilizar essa política.

Viladarga1 (2002, p. 01) cita uma afirmação da coordenadora da área de genéricos da Agência Nacional de Vigilância Sanitária (ANVISA), Vera Valente, que relata: "Muitas indústrias perderam interesse em manter suas marcas, ou saíram do mercado ou passarão a vender genéricos”.

Oliveira (1997, p. 49) comenta que: “O mercado mundial é controlado por marcas de fantasia, demonstrando o casamento perfeito de uma droga eficaz, de preferência, única, com um marketing pesado junto ao médico".

De acordo com Zaché (2003), dados da associação Pró-Genéricos, mostram que há três anos existiam 13 registros de medicamentos genéricos na
Agência Nacional de Vigilância Sanitária (ANVISA), hoje são cerca de 700 registros.

A SOBRAVIME (1999, p. 01) afirma que:

As estratégias para os medicamentos genéricos se baseiam em duas características principais: o uso generalizado de nomes não patenteados ou genéricos para os produtos farmacêuticos, e a disponibilidade de uma seleção de produtos equivalentes (medicamentos genéricos) que podem ser identificados como substitutos e competir em função dos preços.

O mercado de genéricos é capaz de reduzir os preços dos medicamentos cujas patentes expiraram.

Teixeira (2002) cita o medicamento de marca Renitec, cujo fabricante reduziu tanto o preço do medicamento que ficou mais barato que o genérico, Maleato de Enalapril. Ainda, Vilardaga (2002) comenta que a indústria farmacêutica Eurofarma consegue vender o medicamento antidepressivo Fluxene, similar ao Prozac, por um preço $40 \%$ mais baixo do que o de seus concorrentes genéricos, à base de cloridrato de fluoxetina.

Não se pode esquecer que os fabricantes de medicamentos genéricos não oferecem o mesmo 
serviço que os fabricantes inovadores, pois estes não investem em pesquisa, uma vez que o princípio ativo de seus medicamentos já é conhecido.

O objetivo de uma política de medicamentos genéricos é a competição de preços mediante o aumento da oferta de medicamento, bem como, impedir a proliferação de produtos farmacêuticos inaceitáveis.

Quadro 09 - Benefícios para o País

\begin{tabular}{|c|c|c|c|c|}
\hline \multicolumn{2}{|c|}{ B E N E F Í C I O s } & P A R A & P A Í S & \\
\hline \multicolumn{5}{|c|}{ Investimento e Geração de Novos empregos } \\
\hline \multirow{2}{*}{ Indústrias } & \multicolumn{2}{|c|}{ Investimento em $R \$$ (milhões) } & \multicolumn{2}{|c|}{ Geração de novos empregos } \\
\hline & Realizados & Previstos & Ativados & Previstos \\
\hline $\mathrm{N}$ a cion $\mathrm{n}$ is & 369,6 & 128,1 & 3300 & 1250 \\
\hline$M$ ultin a cion a is & 79,7 & 230,5 & 530 & 850 \\
\hline Total & 449,3 & 358,6 & 3830 & 2100 \\
\hline \multicolumn{5}{|l|}{ Fonte: ANVISA } \\
\hline 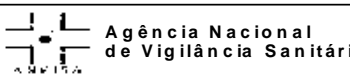 & & & & w w w.a \\
\hline
\end{tabular}

* Referente ao período de setembro de 2001 a agosto de 2002.

Fonte: < www.anvisa.gov.br/hotsite/genericos/index.htm >

Pode-se dizer que os genéricos representam mais uma indústria que concorre no setor das indústrias farmacêuticas, possibilitando uma alternativa de acesso a medicamentos para a população brasileira, independentemente da sua posição social, e ainda, uma alternativa para o governo no que se refere à assistência à saúde. Também no que se refere à geração de emprego, tem-se um benefício para o país, só que não se deve esquecer da qualidade e da vigilância nos testes dos medicamentos dessas empresas.

Vilardaga1 (2002, p. 01) relata: “Aqueles que decidiram vender genéricos têm apresentado boas taxas de crescimento, mas terão, em breve, uma concorrência multinacional qualificada e beneficiada pela produção própria de matérias-primas e pela larga escala demanufatura”.

Observa-se que junto com o objetivo de diminuir o preço dos medicamentos, a lei dos medicamentos genéricos está apresentando uma tendência de expansão de mercado industrial. Todavia, levanta-se uma preocupação: esse crescimento manterá os preços baixos e possibilitará investimentos em pesquisa e desenvolvimento de outras drogas para doenças que ainda não têm cura ou tratamento? 
Quadro 10 - Indústrias de medicamentos genéricos

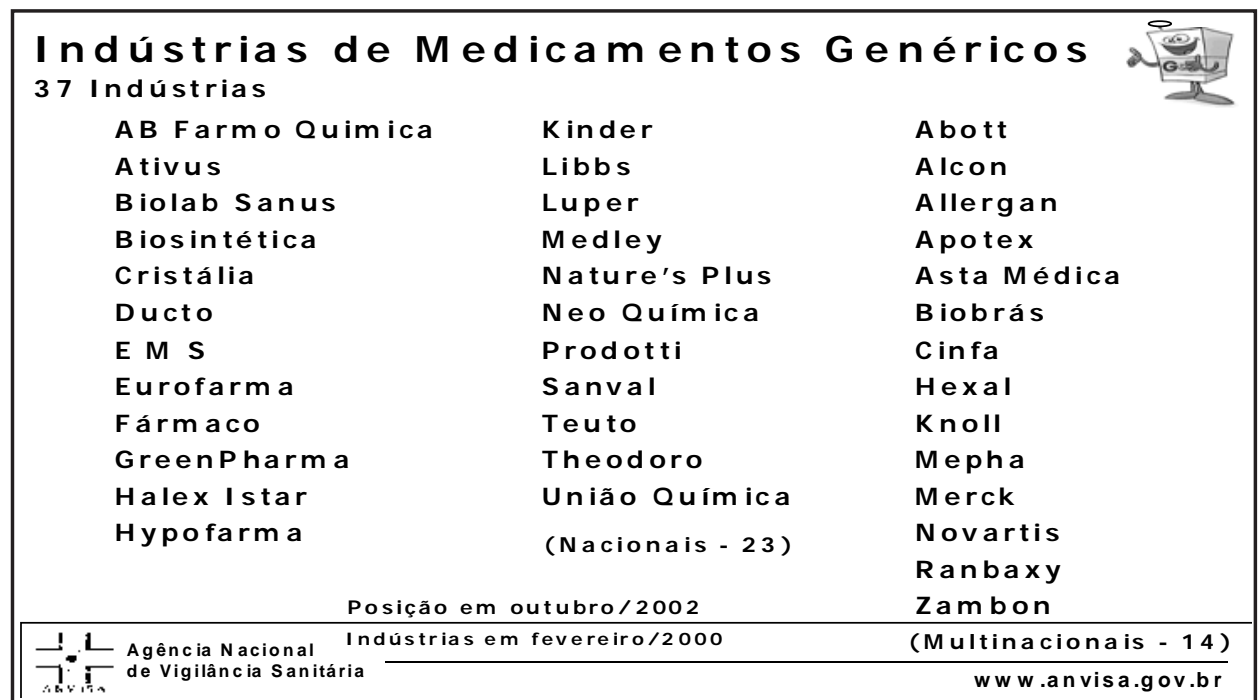

Fonte: < www.anvisa.gov.br/hotsite/genericos/index.htm >

De acordo com Zaché (2003), no início da introdução da lei de medicamentos genéricos, 23 empresas abasteciam o mercado brasileiro; até o início de 2003 já são 37.

A idéia do favorecimento à produção e consumo de medicamentos sem marca suscitou uma verdadeira guerra com a grande indústria farmacêutica, que investe na pesquisa de novos medicamentos. Tudo isso representa novos custos para os laboratórios, forçando as fusões de empresas ou a absorção das menores pelas de maior porte. Por outro lado, garantirá o acesso da população a medicamentos que eram caros, aumentando a possibilidade de aquisição, especialmente pelos menos favorecidos.

A possibilidade de os medicamentos genéricos não serem eficazes gera insegurança na população e entre os médicos, o que só beneficia o interesse da grande indústria, que usufrui o seu poder de marketing para continuar a vender medicamentos a preços exorbitantes.

Quadro 11 - Mercado de medicamentos genéricos no Brasil.

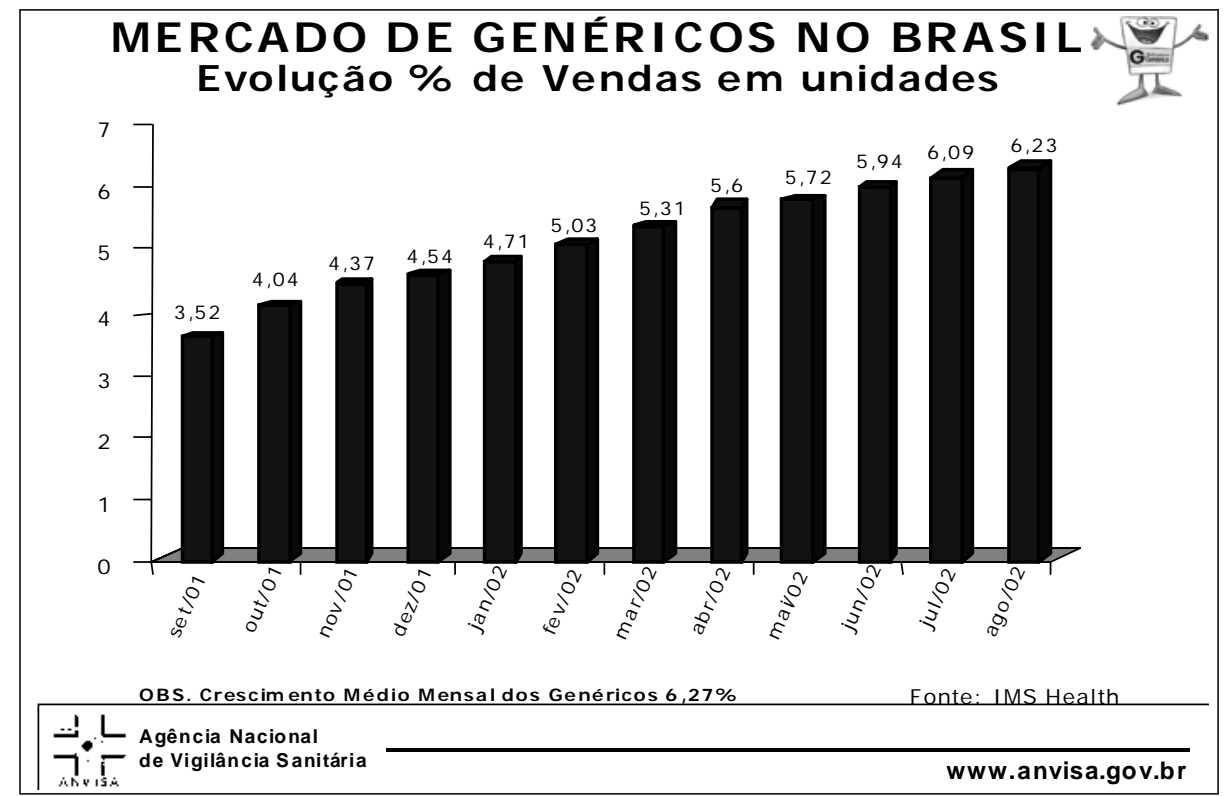

Fonte: < www.anvisa.gov.br/hotsite/genericos/index.htm > 
Conforme Zaché (2003), só em 2002 foram vendidos 73 milhões de unidades de medicamentos genéricos.

A evolução do gráfico que se acaba de apresentar mostra o crescimento nas vendas de unidades de medicamentos genéricos, mostrando um mercado em ascensão e com grande perspectiva de continuar seu crescimento devido à circulação do produto.

Segundo Vilardaga2 (2002, p. 02), “Os laboratórios nacionais que decidiram entrar no mercado de genéricos acertaram. O esforço do governo federal em estabelecer uma nova política de medicamentos criou um negócio que mal existia há dois anos e que já movimenta hoje perto de US\$ 300 milhões”. Os genéricos têm sido o principal caminho para o crescimento da indústria nacional de medicamentos.

Para Pereira (1992), o preço de entrada dos genéricos é muito inferior aos de seus competidores de marca e declina ainda mais com a entrada de novos genéricos. A participação de mercado dos genéricos aumenta com o número de indústrias, mas no tocante ao preço a concorrência não é significativa, pois não existem grandes diferenças de preços entre os próprios medicamentos genéricos.

\section{Considerações finais}

Na década de 1970, diante da crise financeira internacional e do aumento dos gastos com saúde, uma das estratégias encontradas nos países ricos para a redução de despesas foi promover a comercialização de medicamentos genéricos. Além de mais baratos, pela ausência de patentes e marcas, fantasia, os genéricos são medicamentos com eficácia e segurança bem conhecidas.

Pelo que foi relatado até o presente momento, observa-se que os medicamentos genéricos possibilitam à população em geral a diminuição de gastos com medicamentos.

É ilusório achar que todos os brasileiros vão estar cobertos pela Lei do Genérico, pois grande parte da população não tem acesso a ele, levando-se em conta a situação sócio-econômica do país.

O governo mexeu com um setor e o estimulou a produzir determinados tipos de medicamentos mais consumidos pela população, para facilitar, também às pessoas de menor poder aquisitivo, medicamentos seguros e baratos. O governo deveria estimular a fabricação de produtos farmacêuticos genéricos por um parque industrial nacional, incluindo a produção de matérias-primas e dos demais insumos necessários para a fabricação desses medicamentos.

Os medicamentos genéricos desmotivam a pesquisa de novos medicamentos?

A política de medicamentos genéricos é um dos instrumentos necessários, mas a atenção à saúde deve ser o foco principal, visto que é fundamental e economicamente viável uma política governamental de prevenção às doenças. Por que a preocupação com os medicamentos foca apenas as conseqüências e não as causas, se o custo para tratar as conseqüências é maior do que o da prevenção?

\section{REFERÊNCIAS}

1 ANVISA. XXXIV Congresso da Sociedade Brasileira de Farmacologia e Terapêutica Experimental.

2 “Política de Medicamentos Genéricos no Brasil”. Disponível em: < www.anvisa.gov.br/hotsite/genericos/ index.htm > Acessado em: 12 dez. 2002.

3 BERMUDEZ, J. A. Z.Medicamentos: uma questão polêmica. Ciência Hoje, São Paulo, v. 27, n. 161, p. 60-62, jun. 2000.

4 BERMUDEZ, J. A. Z. Indústria Farmacêutica, Estado e Sociedade: Crítica da Política de Medicamentos no Brasil. São Paulo: Hucitec, 1995.

5 BRANDÃO, A. As flores do mal, as flores do bem. Revista Pharmacia Brasileira. Ano II, n. 16, set/out 1999.

6 CODETEC. A Indústria Farmacêutica. Diagnóstico e Perspectivas. Campinas: CODETEC, 1991.

7 LA REVUE PRESCRIRE.Médicaments géneriques: ni anges ni démons. Tradução de Maria Soledad Navarrete. França [S. l.]: n. 118, 1992.

8 OLIVEIRA, G. G. de A.A Indústria Farmacêutica e o Controle Internacional de medicamentos. Brasília: Gráfica do Senado, 1997.

9 PEREIRA, H. M. S.Patente na Indústria Farmacêutica: A Adoção de Patentes e o Acesso a Produtos Farmacêuticos no Brasil. 1. ed. São Paulo: USP, 1992.

10 QUEIROZ, S. R. R. Estudo da Competitividade da Indústria Brasileira. 1. ed. Campinas: UNICAMP, 1993.

11 SANTOS, J. de S. Genéricos são bandeira de todos. 
Pharmacia Brasileira. São Paulo, v. 2, n. 15, p. 05-09. Entrevista.

12 SERRA, J. Ampliar o Possível: a política de saúde do Brasil. São Paulo: Hucitec, 2000.

13 SERRA, J. Os Genéricos e o Mercado Brasileiro. Revista Genéricos Pró Saúde. São Paulo, ano I, n. 1, p. 04-05, maio 2001. Entrevista.

14 SOBRAVIME. Medicamentos Genéricos Sim, Desde Que Essenciais. São Paulo: Sobravime, boletim 34, p. 01-02, jul/set 1999.

15 TEIXEIRA, G. Multinacionais chegam ao Brasil para disputar vendas de genéricos. Gazeta Mercantil. São Paulo, 20 de mai. 2002. Indústria \& Serviços, p. C-1.
16 TEIXEIRA, S. M. F. As Ciências sociais em saúde no Brasil.In. NUNES, E. D. (org.). As ciências sociais em saúde na América latina. Tendências e perspectivas. Brasília: OPS, 1985.

17 VILARDAGA1, V. Mercado prepara-se para a reformulação. Gazeta Mercantil. São Paulo, 13 de jun. 2002. O Futuro da Indústria Farmacêutica, Relatório Gazeta Mercantil, p. 01.

18 VILARDAGA2, V. Os desafios das companhias nacionais. Gazeta Mercantil. São Paulo, 13 de jun. 2002. O Futuro da Indústria Farmacêutica, Relatório Gazeta Mercantil, p. 02.

19 ZACHÉ, J. Dúvida no Ar. Isto É, São Paulo, n. 1740, p. 42-45, 05 mai. 2003. 